\title{
Cellular remodeling and JAK inhibition promote zygotic gene expression in the Ciona germline
}

\author{
Naoyuki Ohta ${ }^{\star, 1}$ and Lionel Christiaen ${ }^{\star, 1,2,3}$ \\ ${ }^{1}$ Center for Developmental Genetics, Department of Biology, \\ New York University, New York, NY, USA \\ ${ }^{2}$ Sars International Centre for Marine Molecular Biology, University of Bergen, Bergen, Norway \\ ${ }^{3}$ Department of Heart Disease, Haukeland University Hospital, Bergen, Norway
}

* Authors for correspondence: no22@nyu.edu (NO) , lc121@nyu.edu (LC), lionel.christiaen@uib.no (LC)

\begin{abstract}
During development, remodeling of the cellular transcriptome and proteome underlies cell fate decisions and, in somatic lineages, transcription control is a major determinant of fateful biomolecular transitions. By contrast, early germline fate specification in numerous vertebrate and invertebrate species relies extensively on RNA-level regulation, exerted on asymmetrically inherited maternal supplies, with little-to-no zygotic transcription. However delayed, a maternal-to-zygotic transition is nevertheless poised to complete the deployment of pre-gametic programs in the germline. Here, we focused on early germline specification in the tunicate Ciona to study zygotic genome activation. We first demonstrate that a peculiar cellular remodeling event excludes localized postplasmic mRNAs, including Pem-1, which encodes the general inhibitor of transcription. Subsequently, zygotic transcription begins in Pem-1-negative primordial germ cells (PGCs), as revealed by histochemical detection of elongating RNA Polymerase II (RNAPII), and nascent transcripts from the Mef2 locus. Using PGC-specific Mef2 transcription as a read-out, we uncovered a provisional antagonism between JAK and MEK/BMPRI/GSK3 signaling, which controls the onset of zygotic gene expression, following cellular remodeling of PGC. We propose a 2-step model for the onset of zygotic transcription in the Ciona germline, which relies on successive cellular remodeling and JAK inhibition, and discuss the significance of germ plasm dislocation and remodeling in the context of developmental fate specification.
\end{abstract}

\section{Introduction}

During embryonic development, defined transitions in the composition of the cellular transcriptome and proteome govern successive cell fate decisions ${ }^{1}$. Common features of fateful molecular transitions include (1) multilineage priming, whereby multipotent progenitors co-express determinants of distinct and mutually exclusive cellular identities ${ }^{2-4}$, (2) de novo gene expression, which adds to primed factors and completes fate-specific cellular programs $^{5,6}$, and (3) cross-antagonisms, whereby competing cellular programs inhibit each other upon mutually exclusive fate choices7. Transcriptional control exerts a dominant influence on these molecular transitions. Transcription regulators are thus widespread determinants of cell fate decisions, especially in somatic lineages ${ }^{8-10}$.

In mammals, early germ cell fate specification is also controlled by signal-mediated induction and transcriptional regulation ${ }^{11-14}$. By contrast, in other vertebrate species such as zebrafish and Xenopus, and in numerous invertebrate species, including the fly Drosophila, the nematode worm C. elegans and the ascidians Halocynthia and Ciona, early germ cell progenitors are 
transcriptionally silent ${ }^{15-17}$. This transcriptional quiescence contributes to keeping germline progenitor cells from assuming somatic fates in response to inductive signals from surrounding cells in early embryos ${ }^{18,19}$. In these systems, the germline is set aside through unequal cleavages and asymmetric divisions, which segregates somatic lineages from primordial germ cells (PGCs), where transcription remains initially silent.

Early unequal cleavages are coupled with polarized distribution of maternal components including the germ plasm, which carries global transcription inhibitors known in several invertebrate species, such as Pgc (polar granule component) in Drosophila, PIE-1 in $C$. elegans $^{20-24}$, and Pem-1 in ascidians ${ }^{16,17}$.

Remarkably, although Pgc, PIE-1 and Pem-1 are unrelated proteins thought to have emerged independently in their corresponding phylogenetic lineages, they all inhibit transcription by blocking phosphorylation of Serine 2 in heptapeptide repeats of the C-terminal domain of RNA Polymerase II (RNAPII-CTD), which is necessary for transcriptional elongation.

Consistent with progressive segregation of transcriptional quiescence from the whole egg and early blastomeres to primordial germ cells, Pgc, Pie-1 and Pem-1 gene products are among the maternal components that constitute the germ plasm and progressively segregate to $\mathrm{PGCs}^{25-27}$. In ascidians, Pem-1 belongs to a group of so-called postplasmic RNAs that are maternally deposited, accumulate to the vegetal-posterior end of the fertilized egg, and are inherited by the earliest germline progenitor cells, named B4.1, B5.2, B6.3 and B7.6, through subsequent unequal cleavages (Figure $1 \mathrm{D} ;{ }^{28,29}$ ). Consistent with the dominant effect of RNAPII inhibition by Pem-1, this lineage remains transcriptionally silent until an unknown stage.

Remarkably, when B7.6 blastomeres "divide" during gastrulation, Pem-1 mRNAs

\footnotetext{
1 As we show in this study, B7.6 cells do not actually divide, and the previously named B8.11 cell is actually a
}

are asymmetrically inherited by only one of the "daughter cells", previously named B8.11, whereas B8.12, its Pem-1 RNA-negative sibling, constitutes the bona fide primordial germ cell (PGC), the progeny of which will later populate the somatic gonad in post-metamorphic juveniles ${ }^{30}$. Since Pem-1 mRNAs are not inherited by PGCs, Pem-1 is likely dispensable for subsequent deployment of the germline-specific program in PGCs.

By contrast with Pem-1 and several other postplasmic RNAs, mRNAs encoding the Vasa homolog Ddx4, a conserved RNA helicase involved in germ cell development in a broad range of species, are distributed into both Pem-1+ remnants and the $\mathrm{PGCS}^{30}$. Taken together, these observations suggest that maternal determinants of germline fate specification comprise both inhibitors of early somatic specification and primed regulators of the germline program, which segregate upon division of B7.6 blastomeres. Here, we hypothesize that exclusion of Pem-1 licenses zygotic gene expression in PGCs, thus permitting the activation of de novo-expressed factors that complement the germline specification program.

More than 40 maternal RNAs have known postplasmic localization in the zygote and early ascidian embryo ${ }^{31-33}$. By contrast, there is limited-to-no information about zygotically expressed genes in the Ciona germline. Contrary to somatic lineages ${ }^{34-37}$, general transcriptional quiescence has precluded traditional whole genome assays from informing early germline gene regulatory networks (GRNs).

Here, by monitoring the B7.6 lineage in Ciona embryos, we first observed that exclusion of Pem-1 RNAs from the PGCs occurs, not by cell division as previously thought, but through a peculiar cell remodelling event that sheds postplasmic RNA-containing cytoplasm at the beginning of gastrulation. This cellular remodeling is followed by initiation of transcription through

cellular fragment, which we herein call the lobe, by analogy with a phenomenon described in $C$. elegans. 
the consecutive onsets of RNAPII activity and Mef2 transcription, at neurula and tailbud stages. Finally, we uncovered a provisional antagonism between JAK and

MEK/BMPR/GSK3 signaling that controls the timing of zygotic transcription initiation in the germline. Taken together, these results shed new light on an important transition in early germline development.

\section{Materials and Methods}

Animals

Wild-type animals of Ciona robusta (aka Ciona intestinalis type A) were collected by M-Rep (Marine Research and Educational Products'), in San Diego, CA. Eggs and sperm were surgically collected from mature adults. Chorion of fertilized eggs were removed by Sodium thioglycolate and Proteinase as described ${ }^{38}$. Dechorionated eggs were cultured on agarose coated Petri dishes in TAPS-buffered artificial sea water (ASW; Bio actif sea salt, Tropic Marin).

\section{Dil cell tracing}

CellTracker CM-DiI Dye (Thermo Fisher Scientific) was dissolved in DMSO (Fisher Scientific) to $1 \mathrm{mg} / \mathrm{mL}$ as previously reported ${ }^{39}$. The DiI solution was sprayed with a microneedle onto B7.6 cells of 64-cell stage embryos. These embryos were allowed to develop, fixed with MEM-FA or MEM-PFA (3.7\% Formaldehyde or 4\% Paraformaldehyde, o.1M MOPS, $0.5 \mathrm{M} \mathrm{NaCl}, 1 \mathrm{mM}$ EGTA, 2 $\mathrm{mM} \mathrm{MgSO}_{4}$ ), and used for antibody staining and/or fluorescent in situ hybridization.

\section{Electroporation}

DNA plasmids were purified by Nucleobond (Macherey Nagel). Thirty or 5oug DNA plasmids of Nkx2-1>Sar1DN and Nkx2-1>DynmDN were introduced to dechorionated eggs with 6oug of Nkx2-1>hCD4::mCherry. We followed the protocol of previous reports to do electroporation ${ }^{40}$. We cultured experimental embryos at $18^{\circ} \mathrm{C}$ by Stage 16 , 8 hpf.

\section{Antibody staining}

We used an antibody for RNA polymerase II as per a previous report ${ }^{17}$; CTD-pSer2 (Abcam, ab5095, 1:500 dilution). We followed the previously described protocol ${ }^{35}$ with slight modification. A rabbit anti human phospho-JAK2 (Y931) antibody (Thermo Fisher Scientific, PA5-104704) was used as a primary antibody, 1/500 in Can Get Signal
Immunostain Solution A (TOYOBO). The antibody was detected by an anti-rabbit-HRP goat antibody 1/500 in Can Get Signal Immunostain Solution A (TOYOBO), and by Tyramide Signal Amplification (Perkin Elmer) as previously described ${ }^{35}$.

\section{In situ hybridization}

DNA fragments were amplified by PCR with exTaq-HS (Takara Bio) and Phusion HF (New England Biolabs) DNA polymerases from Ciona genomic DNA or cDNA. The primers that we used were summarized in Supplemental table S1. The amplicons were subcloned into TOPO vectors (life technologies). DIG or fluorescein labeled RNA probes were synthesised by T7 and sp6 RNA polymerases (Roche) from template DNA plasmid digested by NotI or SpeI (New England Biolabs), and were cleaned by RNeasy mini kit (QIAGEN). We followed the protocol for in situ hybridization described before ${ }^{35,41}$. We detected fluorescein and DIG probes using TSA plus (Perkin Elmer) green (FP1168) and red (FP1170), respectively. Primer sequences are provided in Supplemental Table S1.

\section{Pharmacological inhibitor treatments}

Actinomycin D (Sigma) was diluted into DMSO at $10 \mathrm{mg} / \mathrm{mL}$ stock. The stock solution was diluted into ASW to a final concentration of $40 \mu \mathrm{g} / \mathrm{mL}$. This concentration was reported to block transcription in Halocynthia embryos ${ }^{42}$. Flavopiridol (Selleck chemicals) was diluted into water to $10 \mathrm{mM}$ stock. The stock solution was diluted into ASW to final concentration 1 and $10 \mu \mathrm{M}$. The transcriptional inhibitor treated embryos were fixed by MEM-PFA (4\% PFA, 0.1M MOPS, 0.5M NaCl, 1mM EGTA, $2 \mathrm{mM} \mathrm{MgSO}_{4}$ ) after 1 hour inhibitor treatment, and used for in situ hybridization.

1-Azakenpaullone (S7193; Selleckchem; ${ }^{43}$ ), Ruxolitinib (INCBo18424; S1378; Selleckchem), Vismodegib (GDC-0449; S1082; Selleckchem), DAPT (Millipore Sigma), SB431542 (S1067; Selleckchem; ${ }^{35}$ ), Uo126 (Cell Signaling Technology; 
${ }^{44}$ ) and Dorsomorphin (Selleckchem; ${ }^{35,43}$ ) were used to perturb define signaling pathways as described in corresponding references. These treatments were done in a final concentration of $10 \mu \mathrm{M}$ for 2 or 4 hours. The inhibitor-treated embryos were fixed by MEM-PFA after 2 hours inhibitor treatment, and used for in situ hybridization.

\section{$\underline{\text { Results }}$}

\section{Cellular remodeling excludes certain maternal postplasmic RNAs from primordial germ cells}

In Ciona embryos, the B7.6 cells give birth to primordial germ cells (PGCs), which are thought to emerge after one more division, and correspond to the B8.12 lineage, following segregation of a subset of maternal postplasmic RNAs into their B8.11 sister cells $^{30,45}$. One of these RNAs, Pem-1, produces a nuclear protein that inhibits zygotic transcription in B7.6 cells, thus protecting the PGC lineage by preventing ectopic activation of somatic determinants ${ }^{16,17}$. Therefore, we reasoned that zygotic genome activation might follow the exclusion of Pem-1 RNA from the PGCs. To address this possibility, we first sought to identify candidate zygotically expressed genes, as well as reliable markers of B7.6 lineage cells. We leveraged the extensive in situ gene expression database ANISEED $^{46-48}$. Among genes encoding Postplasmic/PEM RNAs maternally expressed and localized in the B7.6 lineage, we used Pem-1 (KH.C1.755; ${ }^{32}$ ) as a B8.11 marker, and Ms4a15/2 (KH.C2.4, aka Pem-7; ${ }^{33,49}$ ) as a dual B8.11 /B8.12 marker. Whole mount fluorescent in situ hybridization (FISH) assays confirmed the expected localization of Pem-1 and Ms4a15/2 mRNAs in small B8.11 and large B8.12 cells at the mid tailbud stage (stage $21^{50}$; Figure $\left.1 \mathrm{~A}, \mathrm{~B}\right)$. However, to our surprise, we did not find any DAPI-positive nucleus in Pem-1+ B8.11 "cells" in tailbud embryos (Figure $1 \mathrm{C}-\mathrm{C}$ ').

This observation prompted us to re-evaluate whether B7.6 cells undergo bona fide cell divisions, or cellular remodeling events akin to lobe formation and scission in the primordial germ cells of C. elegans ${ }^{51}$. To this aim, we used cell-specific DiI labeling to monitor B7.6 cell shape changes from the gastrula stage onward (Figure 1D-H'; ${ }^{30,39}$ ). We observed DiI+ cell fragments separate from B7.6 cells (Figure 1 F-G), and lacking DAPI+ nuclei as early as the early neurula stage (Figure 1H-H'). To test whether these B7.6-derived cell fragments correspond to the entities previously recognized as B8.11 cells, we performed fluorescent in situ hybridization using the Pem-1 probe on DiI-labeled neurula stage embryos. This experiment showed colocalization of Pem-1 RNA with B7.6-derived cell fragments in neurula stage embryos (Figure 1I-J). Taken together, these observations indicate that B7.6 cells undergo a cell remodeling event toward the end of gastrulation, which results in the shedding of cytoplasm containing maternal postplasmic RNA including Pem-1, into a cell fragment that we refer to as "the lobe", by analogy with the PGC remodeling process described in $C$. elegans $^{51-54}$. On the other hand, remodeled B7.6 cells, which we propose to call B7.6*, are the bona fide primordial germ cells in Ciona.

\section{The endoderm promotes PGC remodeling}

In various animal species, PGCs associate with endodermal progenitors ${ }^{55,56}$. In C. elegans for instance, intestinal precursors actively phagocytose the germline lobes ${ }^{51}$. In ascidians, B7.6 cells abut the posterior-most endodermal progenitors, and the PGCs remain associated with the intestinal anlage, known as endodermal strand, in the larval tail ${ }^{45,57,58}$. We thus explored a possible involvement of the endoderm in PGC remodeling. We combined fluorescent immuno-histochemical (IHC) staining and whole mount in situ hybridization to jointly detect the endoderm reporter 
Nkx2-1>hCD4::mCherry (Nkx2-1 enhancer driving human cluster of differentiation 4 conjugated to monomeric Cherry fluorescent protein $)^{59,60}$ and the B7.6 lineage marker Ms4a15/2 in neurula stage embryos. These assays indicated that, while the B7.6 cell bodies remained adjacent to, but outside, the endoderm, the lobe appeared wedged in between endoderm progenitor cells (Figure $1 \mathrm{~K}-\mathrm{L}$ ). Likewise, joint visualization of endodermal cell membranes, labeled by Nkx2-1>hCD4::GFP, and DiI-labeled B7.6 cells revealed the close proximity between detached lobes and endodermal progenitors (Figure 1M-O). However, by contrast with $C$. elegans, we did not obtain clear evidence that endoderm cells engulf PGC lobes in Ciona.

Taken together, these data indicate that B7.6 PGC progenitor cells undergo cellular remodeling events that produce cellular fragments, the lobes, which contain maternally deposited postplasmic mRNAs, and remain associated with the posterior endoderm.

Next, we sought to test if the activity of endoderm cells impact PGC lobe formation and/or scission, as is the case in C. elegans. To this aim, we used the endoderm-specific driver $N k x 2-1$ to express dominant negative forms of the GTPases Sar1 (Sar1 ${ }^{\text {DN }}$; KH.C14.601; ${ }^{60}$ ) or Dynamin (Dynm ${ }^{\text {DN }}$; KH.C6.83: ${ }^{51}$, which interfere with Endoplasmic Reticulum-to-Golgi transport or with endocytosis, respectively. We visualized endodermal cell membranes with Nkx2-1>hCD4::mCherry and lobe/B7.6 cells with the Ms4a15/2 marker, that is expressed in both lobes and $\mathrm{B} 7.6^{*}$ cells, at the late neural stage, and scored lobe separation from B7.6* cells (Figure $1 \mathrm{P}-\mathrm{S}$ ). Altered hCD4::mCherry localization in endodermal cells expressing Sar1 ${ }^{\mathrm{DN}}$ confirmed tissue-specific perturbation of the secretory pathway, but did not affect PGC lobe formation and scission (Figure 1P-S). By contrast, perturbation of vesicle scission in endodermal cells altered lobe separation, suggesting that dynamin function in endodermal cells contributes to PGC remodeling (Figure S1). Notably, lobe formation appeared to have resumed at later stages upon inspection of older embryos, which prevented us from formally testing the impact of lobe formation on later events in the PGCs (Figure S1; see discussion). In summary, these observations revealed a role for the endoderm in PGC remodeling, as observed in C. elegans, where dynamin function is also required for lobe phagocytosis and severance from the PGCs.

\section{Cellular remodeling precedes the onset of zygotic transcription in PGCs}

In ascidians, the maternal postplasmic mRNA Pem-1 encodes a nuclear protein that inhibits zygotic transcription ${ }^{16,17}$. Pem-1 acts by blocking phosphorylation of Serine 2 in heptapeptide repeats at the RNA polymerase II C-terminal domain (RNAPII CTD) ${ }^{16}$. We thus reasoned that, by removing Pem-1 mRNA from B7.6 cells, cellular remodeling may contribute to activating zygotic gene expression in the germline. Indeed, previous immunostaining assays indicated that Pem-1 protein localizes to both nucleus and lobe during B7.6 cell remodeling, but became undetectable in PGCs by the tailbud stage ${ }^{17}$. To test whether the removal of Pem-1 licensed zygotic transcription in remodeled PGCs, we DiI-labeled B7.6 cells and fixed embryos between the early gastrula and tailbud stages (6 to 12 hours post fertilization (hpf) at $18^{\circ} \mathrm{C}$; St. 13, 16, 21 and 23) for immunostaining with an anti-RNAPII-CTD-pSer2 antibody (Figure 2A-D). Consistent with previous reports ${ }^{17}$, we did not detect RNAPII-CTD-Ser2 phosphorylation in B7.6 cells at 6 hpf (St. 13). By contrast, the majority of mid-tailbud stage embryos displayed conspicuous RNAPII-CTD-Ser2 phosphorylation in PGC nuclei (2 nuclei at $10 \mathrm{hpf}$, and 4 nuclei at 12 hpf after one cell division of B7.6* cells), from $10 \mathrm{hpf}$ (St. 21) onward. These results indicated that transcription elongation by RNA polymerase II is active in the PGCs of mid tailbud embryos, which follows the exclusion of Pem-1 mRNAs by B7.6 blastomere remodeling. 


\section{Mef2 is zygotically transcribed in the PGCs}

Having established that the PGCs of mid-tailbud embryos are transcriptionally active, we sought to identify genes expressed zygotically in B7.6* cells. We mined the gene expression database ANISEED ${ }^{46-48}$, and identified candidate transcription factor-coding genes possibly upregulated in B7.6* cells after the exclusion of postplasmic RNAs by lobe scission. Here, we focus on a transcription factor coding gene, Myocyte elongation factor 2 (Mef2; KH.S455.6). Mef2 maternal mRNAs were detected ubiquitously in the whole early embryo and intense ISH signals were observed in the muscle, endoderm and epidermis ${ }^{61}$. This abundance of maternal mRNA prevented us from identifying zygotic products with cDNA-derived probes. To specifically monitor zygotic Mef2 expression, we synthesized Mef2-specific intronic probes, which detect nascent transcripts, as shown for Gata4/5/6, Tbx1/1O and $E b f$ in the cardiopharyngeal lineage ${ }^{7,62}$. To unequivocally identify PGCs, we performed double FISH assays with Mef2 intronic probe and the B7.6 lineage marker Ms4a15/2 (Figure $2 \mathrm{E})$. Mid- to late tailbud embryos raised at $18^{\circ} \mathrm{C}$, and collected in a time series between 10 and 15 hpf, St. 21-24, showed conspicuous nuclear dots of nascent transcripts, indicative of zygotic Mef2 expression in B7.6*, as well as epidermal and muscle cells (Figure 2E).

Because transcription was shown to occur in bursts of RNA polymerase activity in other systems ${ }^{63,64}$, and our assay provided snapshots of dynamic nuclear states, we reasoned that Mef2 loci in B7.6* cells might be transcriptionally active and yet show 0,1 or 2 dots (assuming that even after DNA replication, sister chromatids remain too close to distinguish by standard confocal microscopy). We thus counted Mef2+ dots per B7.6* nucleus at successive stages, to obtain a semi-quantitative view of transcriptional activity at the Mef2 locus in developing PGCs. This analysis indicated that zygotic Mef2 expression peaked at the late tailbud I stage (st. $23,12 \mathrm{hpf}$ at $18^{\circ} \mathrm{C}$ ), from an onset around $10 \mathrm{hpf}$, and was markedly down-regulated by 15 hpf (Figure 2F).

At its peak, we detected 1 or 2 fluorescent dots in $50 \%$ of the nuclei, and thus sought to further verify that these correspond to active Mef2 transcription. We treated embryos with known chemical inhibitors of transcription and assayed zygotic Mef2 expression with our intronic probe. Actinomycin D, an established transcription inhibitor that binds "melted" DNA at the pre-initiation complex and prevents RNA elongation ${ }^{65}$, was previously used on ascidian embryos ${ }^{30,42}$, and caused a significant but modest down-regulation of Mef2 expression in B7.6* cells (Figure S2E). On the other hand, the CDK9 inhibitor Flavopiridol, which also blocks transcriptional elongation, but by preventing RNAPII-CTD-Ser2 phosphorylation ${ }^{66}$, nearly eliminated Mef2+ nuclear dots (Supplemental Figure S2A-E). In either case, chemical inhibitor treatments supported the interpretation that intronic probe-positive nuclear dots represent nascent transcripts, which is indicative of zygotic Mef2 expression in the PGCs during the tailbud developmental period. Notably, the temporal profile of zygotic Mef2 expression showed an onset that followed both B7.6 cell remodeling and the global activation of RNA Polymerase II. This is consistent with a causal chain of events whereby postplasmic RNA exclusion through cellular remodeling helped relieve the Pem-1 break on RNAPII activity, thus permitting subsequent zygotic gene expression in the PGCs.

\section{JAK signaling delays the onset of zygotic Mef2 expression in B7.6* cells}

Having established that cellular remodeling precedes global RNAPII licensing and the onset of Mef2 transcription in B7.6* cells, we sought to identify regulators of zygotic Mef2 expression in the PGCs. We reasoned that signaling inputs from surrounding cells probably contribute to initiating zygotic gene expression in B7.6* 
cells, and their possible roles are readily testable by pharmacological inhibition. Treatments with Uo126 (10 $\mu \mathrm{M} ; 10-12 \mathrm{hpf}$; St. 21-23), Dorsomorphin (10 $\mu \mathrm{M} ; 10-12 \mathrm{hpf})$ and 1-Azakenpaullone (10 $\mu \mathrm{M} ; 10-12 \mathrm{hpf})$, which inhibit MEK1/2, BMPRI and GSK3, respectively, significantly reduced the proportions of nuclei with detectable nascent Mef2 transcripts in Ms4a15/2+ PGCs (Supplemental Figure S3). However, neither of these inhibitors completely abolished zygotic Mef2 expression. We tested whether these signaling pathways act additive, by combining the three inhibitors in a condition referred to as " $3 \mathrm{i}$ " (10 $\mathrm{MM}$ each; 10-12hpf), which indeed caused the most marked decrease in zygotic Mef2 expression in B7.6* cells (Figure 3A-B, E). This suggested that MEK, BMPR and GSK$_{3}$, whose sources are at the tail tip and ventral side of the tail ${ }^{43,61,67,68}$, act at least partially additively to promote zygotic Mef2 expression in the PGCs.

By contrast with the 3 i treatment, the JAK inhibitor Ruxolitinib (10 $\mu \mathrm{M} ; 10-12 \mathrm{hpf})$ significantly increased the fraction of PGCs with $M e f 2+$ nuclei, in addition to inhibiting B7.6* cell division and tail elongation (Figure $3 \mathrm{C}, \mathrm{E}-\mathrm{F}$ ). To test a possible hierarchy between the signaling pathways that regulate $M e f 2$ transcription in the PGCs, we combined the $3 \mathrm{i}$ and Ruxolitinib treatments (Figure $3 \mathrm{D}-\mathrm{E}$ ). This combination also increased the proportions of the Mef2+ nuclei, to levels similar to those obtained with Ruxolitinib alone. Taken together, these results suggest that JAK signaling inhibits zygotic Mef2 expression in B7.6* cells, while MEK, BMPR and $\mathrm{GSK}_{3}$ act additively to promote $M e f 2$ transcription, primarily by antagonizing JAK activity.

To gain further insights into the biological significance of inhibitor treatments and better characterize the context in which JAK signaling regulates zygotic Mef2 expression in the PGCs, we assayed endogenous JAK activity in Ciona embryos. Previous genome-wide surveys identified one Jak ortholog in the Ciona genome ${ }^{69}$, and one region surrounding actively phosphorylated tyrosines is conserved with human JAK2 (Figure S4A). We thus tested an anti human phospho-JAK2 (Y931) polyclonal antibody to detect endogenous JAK activity in tailbud embryos, and observed conspicuous signal in tail tip and dorsal midline cells (Figure 3G, I). Treatment with the JAK inhibitor Ruxolitinib abolished the signal, thus validating antibody specificity (Supplemental Figure S4B-G). JAK activity was most conspicuous at the tail tip of St. 21 embryos (10 hpf at $18^{\circ} \mathrm{C}$ ), and markedly reduced by St. $23\left(12 \mathrm{hpf}\right.$ at $\left.18^{\circ} \mathrm{C}\right)$, which coincides with peak transcriptional activity of the Mef2 locus in the germline (Figure 2F). While this pattern is consistent with concomitant down-regulation of JAK signaling and activation of Mef2 expression, as well as the effect of Ruxolitinib treatments, the latter do not distinguish between cell autonomous and non cell autonomous effects. To evaluate the possibility that JAK acts

cell-autonomously upstream of Mef2 in the PGC lineage, we DiI-labeled B7.6 cells and assayed JAK activity at two developmental stages corresponding to the onset and peak of zygotic Mef2 expression (Figure $3 \mathrm{G}-\mathrm{K}$ ). This experiment revealed JAK activity in B7.6* cells at St. $21\left(10 \mathrm{hpf}\right.$ at $\left.18^{\circ} \mathrm{C}\right)$, but reduced signaling by St. $23\left(12 \mathrm{hpf}\right.$ at $\left.18^{\circ} \mathrm{C}\right)$.

Leveraging anti-pJAK immunostaining, we tested whether MEK, BMPR and GSK3 signaling contribute to inhibiting JAK phosphorylation by stage 23 by staining embryos treated with the $3 i$ cocktail of inhibitors (Figure $\mathrm{S}_{5}$ ). We observed no conspicuous difference between $3 \mathrm{i}$ and DMSO control treatments, indicating that pJAK inhibition occurs independently of MEK, BMPRI, GSK3 signaling inputs (Figure $\mathrm{S}_{5}$ ).

Taken together, our observations are consistent with the possibility that JAK signaling plays an early cell-autonomous role in delaying the peak of Mef2 transcription in the PGCs. Indeed, RNA polymerase II is licensed to initiate transcription as early as 8 hpf (Figure 2D; St. 16), while zygotic $M e f 2$ expression does not start before $10 \mathrm{hpf}$, and 
only peaks at $12 \mathrm{hpf}$ (Figure 2F). To test if JAK signaling inhibits early Mef2 expression, we thus treated embryos with Ruxolitinib from 8 hpf onward (St. 16), and assays zygotic Mef2 expression at $10 \mathrm{hpf}$ (Figure $3 \mathrm{~L}-\mathrm{O}$ ). In control DMSO-treated embryos, at most $25 \%$ of the B7.6 lineage nuclei showed nascent Mef2 transcripts. By contrast, we detected active Mef2 transcription in approximately $50 \%$ of the B7.6 lineage nuclei following treatment with the JAK inhibitor between 8 and $10 \mathrm{hpf}$ (St. 16-21; Figure 3L-O). Moreover, 8 to $12 \mathrm{hpf}$ (St. 16-23) treatments resulted in similar $\sim 50 \%$ of $M e f 2^{\text {intron }}+$ B7.6 lineage nuclei, albeit with a lower fold-increase, as the DMSO baseline was at $41 \%$, suggesting that Mef2 transcription peaks earlier following early JAK inhibition. Of note, control B7.6* cells had not divided in the 8 to $10 \mathrm{hpf}$ time window (Figure $30)$. These early treatments thus indicated that chemical JAK inhibition promotes Mef2 transcription independently of its effects on cell division. Taken together, these results support the notion that early cell autonomous JAK activity delays the peak, and probably the onset of zygotic Mef2 expression in the PGCs.

\section{MEK, BMPR, GSK3 and JAK signaling regulate Mef2 transcription independently of RNA polymerase II CTD phosphorylation}

Finally, since global transcription licensing shortly precedes the onset of zygotic Mef2 expression, we tested whether the kinases that influence the production of nascent Mef2 transcripts also impact RNAPII-CTD phosphorylation. To this aim, we repeated the above chemical inhibitor treatments targeting MEK, BMPRI, GSK3 and JAK, and assayed RNAPII-CTD-Ser2 phosphorylation at $8 \mathrm{hpf}$, St. 16 and $12 \mathrm{hpf}$, St. 23. In short, neither of these inhibitor treatments appeared to alter RNA polymerase II activity (Figure 4A-E; Figure S6), suggesting that the kinases regulate zygotic Mef2 expression independently of global RNAPII activation (Figure 4G).

\section{Discussion}

Animal species endowed with "preformed" primordial germ cells illustrate August Weismann's famous dichotomy between mortal somatic vs. immortal germline lineages, and the mechanisms underlying this divergence in early embryos have garnered much attention ${ }^{70-72}$. Despite the de facto immortality and totipotency of their lineage, illustrated by their ability to reconstitute an entire organism upon fertilization and embryogenesis, PGCs eventually assume an identity and differentiate into highly specialized egg and sperm cells, the gametes. As cells, PGCs are thus bound to the same developmental constraints as somatic cells: to choose an identity, which comprises avoiding others, and differentiate accordingly, with the notable distinction that germ cells may postpone terminal differentiation until sexual maturity ${ }^{73-75}$.

This opportunity to pause differentiation may relate to the observed delay in starting zygotic genes in expression in the germline, which is a widespread mechanism used to prevent somatic fate specification ${ }^{76}$. Indeed, the unrelated proteins Pgc, PIE1 and Pem-1 globally prevent zygotic gene expression in the germline by inhibiting phosphorylation of Serine 2 in heptapeptide repeats of the C-terminal domain of RNA Polymerase II, in as diverse animals as Drosophila, Caenorhabditis elegans and ascidians, respectively ${ }^{20-24}$.

This early global inhibition of transcription in PGCs imposes an exclusive reliance on maternal products deposited in the egg during oogenesis ${ }^{77,78}$. Among those, germline-specific components are typically found in RNA-rich germ granules, germ plasm or nuage, and dispatched into PGCs through polarized RNA and protein localization, and asymmetric inheritance following unequal 
cleavages in early embryos ${ }^{78-80}$. In early ascidian embryos, Pem-1 maternal mRNAs are localized and associated with the cortical centrosome attracting body (CAB), segregate asymmetrically at every unequal cleavage, and are found exclusively in B7.6 blastomeres by the 64-cell stage $\mathrm{e}^{79}$.

While Pem-1 keeps B7.6 cells, and their progenitors, transcriptionally quiescent, it does not have a direct role in specifying the germline identity, which is another function that must be partially carried by the germ plasm, in the absence of zygotic gene expression ${ }^{15,76}$. In Ciona, as in numerous other species, the conserved RNA helicase Vasa/Ddx4 is thought to act as a PGC determinant ${ }^{45}$. Vasa/Ddx4 mRNAs and proteins are segregated mainly to B7.6* cells/PGCs, as is the case for P granules in $C$. elegans $^{51,81}$. The germ plasm must thus fulfill two essential, but partially antagonistic functions for germline specification: (1) inhibiting the alternative somatic fate specification through transcriptional silencing, and (2) promoting the acquisition of germ line-specific molecular features, including transcriptional activation of a zygotic germline program. We must thus anticipate that germ plasm remodeling and segregation of anti-somatic and pro-germline activities is essential for germline development. Consistent with this assertion, germ plasm remodeling has been observed, and segregation of its components is important for germline development in flies ${ }^{80}$ and zebrafish $^{82}$.

Here, we presented data that corroborate previous observations about the dislocation of the germ plasm and differential segregation of its components in Ciona, and showed that this results from a peculiar cellular remodelling event rather than unequal cleavage, as previously thought, that is similar to ascidian, Oikopleura dioica ${ }^{8}$. Because B7.6 cells had once phospho-histone 3 signals showing their mitotic stage ${ }^{30}$, there still remains a possibility that this cell remodeling event is actual cell division, and degraded nuclei by apoptosis.
Indeed, the vesicle that had been referred to as B8.11 cells is actually not a cell. We propose to call it "lobe", after the analogous entity observed in C. elegans. Moreover, Pem-1 mRNAs are among the postplasmic RNAs that segregate specifically to the lobe ${ }^{33,81}$, ultimately resulting in the elimination of Pem-1 proteins from the PGCs by the tailbud stage ${ }^{17}$. Since Pem-1 globally blocks transcription, we propose that lobe scission is an important step to physically remove postplasmic RNAs from the PGCs and permit further germline specification, in part through zygotic gene expression.

Germline lobe formation and scission exhibit intriguing parallels and differences between Ciona and C. elegans. One of the hallmarks of lobe formation and scission in $C$. elegans is the polarized distribution and removal of most mitochondria from the cell bodies of $\mathrm{PGCs}^{51}$. By contrast, in Ciona embryos, most mitochondria are depleted from B7.6 cells during the asymmetric division of their mother B6.3 cell, which also produces the B7.5 cardiac progenitors that inherit most mitochondria (a.k.a. myoplasm in ascidians) ${ }^{84}$. In Ciona, mitochondria clearance from the germline is thus decoupled from lobe formation.

Another intriguing parallel between germline lobe formation and scission in $C$. elegans and Ciona regards its association with endodermal progenitors. Primordial germ cells exhibit an evolutionary conserved association with the endoderm in a variety of species ${ }^{85,86}$, including Ciona $^{58,87,88}$. The physical proximity between lobes and endoderm cells could thus be shared between Ciona and C. elegans as a byproduct of an ancient association between PGCs and intestine progenitors. Nonetheless, lobe formation in both species is inhibited, at least transiently, by loss of dynamin function in the endoderm ${ }^{51,53}$. By contrast with $C$. elegans, endoderm cells do not appear to engulf and digest germline lobes in Ciona, thus obscuring the exact role of endodermal dynamin in Ciona germline lobe scission, and highlighting differences in the detailed cellular 
events between the two species. Tissue specific gene knock-out of dynamin and its related genes by Cas9-mediated gene knock-out would compensate for our result in the future work.

Finally, much attention has been devoted to the molecular mechanisms underlying germ plasm structure and function during germline formation ${ }^{23,77,78}$. By contrast, less is known about the mechanisms involving cell-cell signaling and zygotic gene expression in early germline specification, with the notable exception of PGC specification in mammals, which is governed by FGF, BMP and Wnt signaling pathways, as well as leukemia inhibitory factor (LIF)-controlled signaling ${ }^{11,89,90}$. Here, having identified one zygotically expressed gene in Ciona PGCs, we began to disentangle the mechanisms governing early genome activation in the germline. Specifically, chemical inhibitor treatments suggest that MEK, BMPRI and
GSK3 contribute to activating $M e f 2$ transcription in the PGCs, providing JAK activity is inhibited. Our observations indicate that early JAK signaling acts independently of Pem-1-mediated inhibition of RNAPII to inhibit Mef2 transcription, and after lobe scission to delay the onset of Mef2 expression. Whereas, further studies will be required to compensate for a weakness of experiments based on only pharmacological inhibitor treatment and to determine the source of signals and the genome-wide extent of zygotic gene expression in the Ciona germline, these results evoke a parallel between the signaling circuits that control germline specification in Ciona, and those that maintain stemness in mammalian pluripotent stem cells, which also rely on active JAK signaling and the concurrent inhibition of MEK and GSK $3^{91-95}$.

\section{Acknowledgments}

We are grateful to Christiaen lab members for discussions and feedbacks. This work was supported by NIH/NIGMS award GMo96032 to L.C. 


\section{Figures}

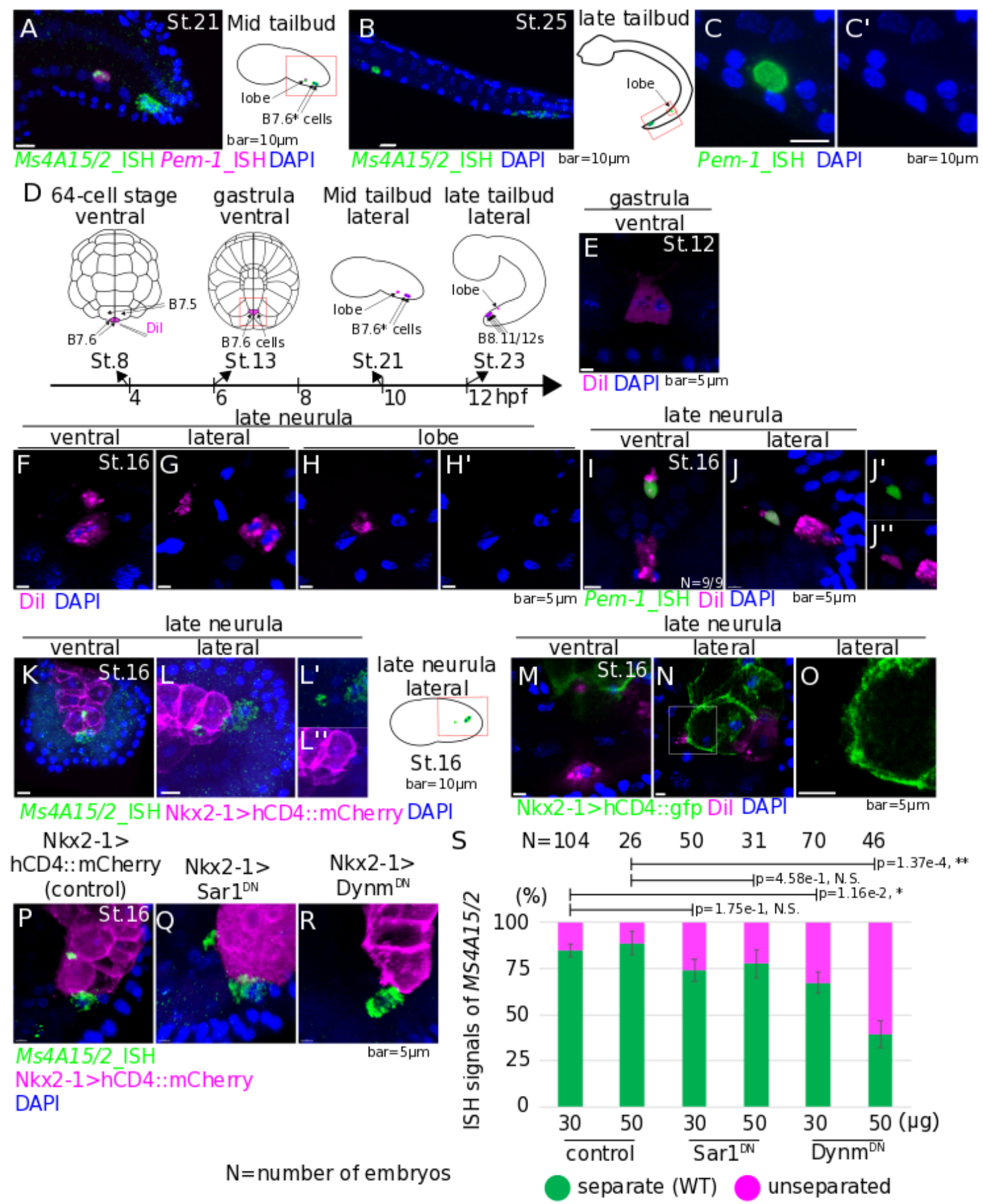

Figure 1. B7.6 cells form lobe with help by endodermal cells. (A) Expression of PGC marker genes, Pem-1 and MS4a15/2 detected by ISH probes corresponding to exons at the mid tailbud stage. St. 21. (B) Expression of $M S 4 a 15 / 2$ at the late tailbud stage, St. 25. (C, C') Expression of Pem-1 in lobe at the late tailbud stage, St. 25. (D) Schematic diagram of Ciona development from 64-cell stage, St. 8 to late tailbud stage, St. 23. Magenta shows DiI label. (E-H') Cell membranes of B7.6 cells were stained by DiI at the 64-cell stage, and taken image at the gastrula (E) and the neurula stages (F-H'). (I-J) B7.6 cells were traced by DiI, and lobe was detected by ISH with a Pem-1 probe corresponding to exons. $\left(\mathrm{J}^{\prime}\right)$ Green and blue channels of J. ( $\left.\mathrm{J}^{\prime \prime}\right)$ Magenta and blue channels of J. (K-L) Both lobe and B7.6* cells were stained by ISH for 
MS4a15/2 gene, and cell membranes of endodermal cells were stained by Nkx2-1>hCD4::mCherry at the late neurula stage, St. 16; ventral (K) and lateral (L) views. (L') Green and blue channels of L. (L") Magenta and blue channels of L. (M-O) Endodermal cell membrane was stained by Nkx2-1>hCD4::gfp in addition to DiI labeling for B7.6 cells. (P-R) Nkx2-1>hCD4::mCherry was used to stain cell membranes of endodermal cells at the late neurula stage. Expressions of MS4a15/2 were detected by ISH: in control (P), Nkx2-1 $>$ Sar $^{\text {DN }}(\mathrm{Q})$ and Nkx2-1 $>$ Dynm $^{\text {DN }}(\mathrm{R})$ embryos. Lateral view from embryo. (S) ISH signals of Ms4a15/2 in lobe and/or B7.6 cells were scored in embryos. The amount of plasmids used for electroporation were 30 or 50 microgram $(\mu \mathrm{g})$. Error bars indicate standard error. p-value was calculated by z-test. p>0.05; N.S, 0.05>p>0.01; * $0.01>$ p; **. Scale bars $=5 \mu \mathrm{m}$ or $10 \mu \mathrm{m}$.

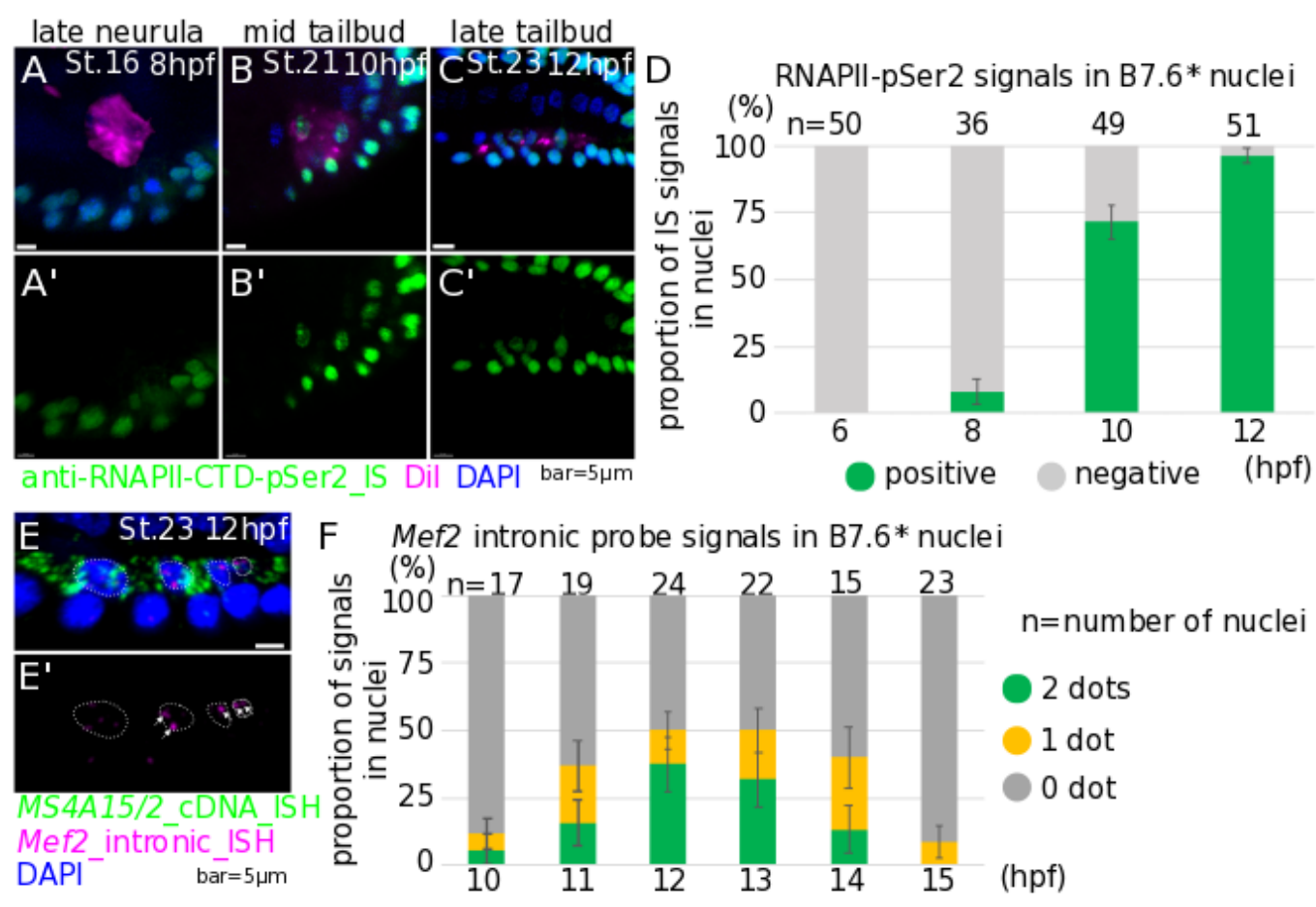

Figure 2. RNA polymerase II Ser2 phosphorylation and Mef2 nascent expression in B7.6* cells. (A-C) Immunostaining for anti-RNAPII-CTD-pSer2 antibody was done at the late neurula; $8 \mathrm{hpf}(\mathrm{A})$, the mid tailbud; $10 \mathrm{hpf}$ (B) and the late tailbud; $12 \mathrm{hpf}$ (C) stages. (D) Proportion of signal positive nuclei by immunostaining with anti-RNAPII-CTD-pSer2 antibody in B7.6* cells. (E-E') Nascent expression of Mef2 gene was detected by $M e f 2$ intronic probes in $12 \mathrm{hpf}$ embryos at $18^{\circ} \mathrm{C}$. White arrows indicate the dotted signals of nascent Mef2 expression in nuclei of B7.6* cells. White dotted circles show nuclei of B7.6* cells. (F) Mef2 intronic probe signals in nuclei in B7.6* cells. Error bars indicate standard error. Scale bars $=5 \mu \mathrm{m}$. 


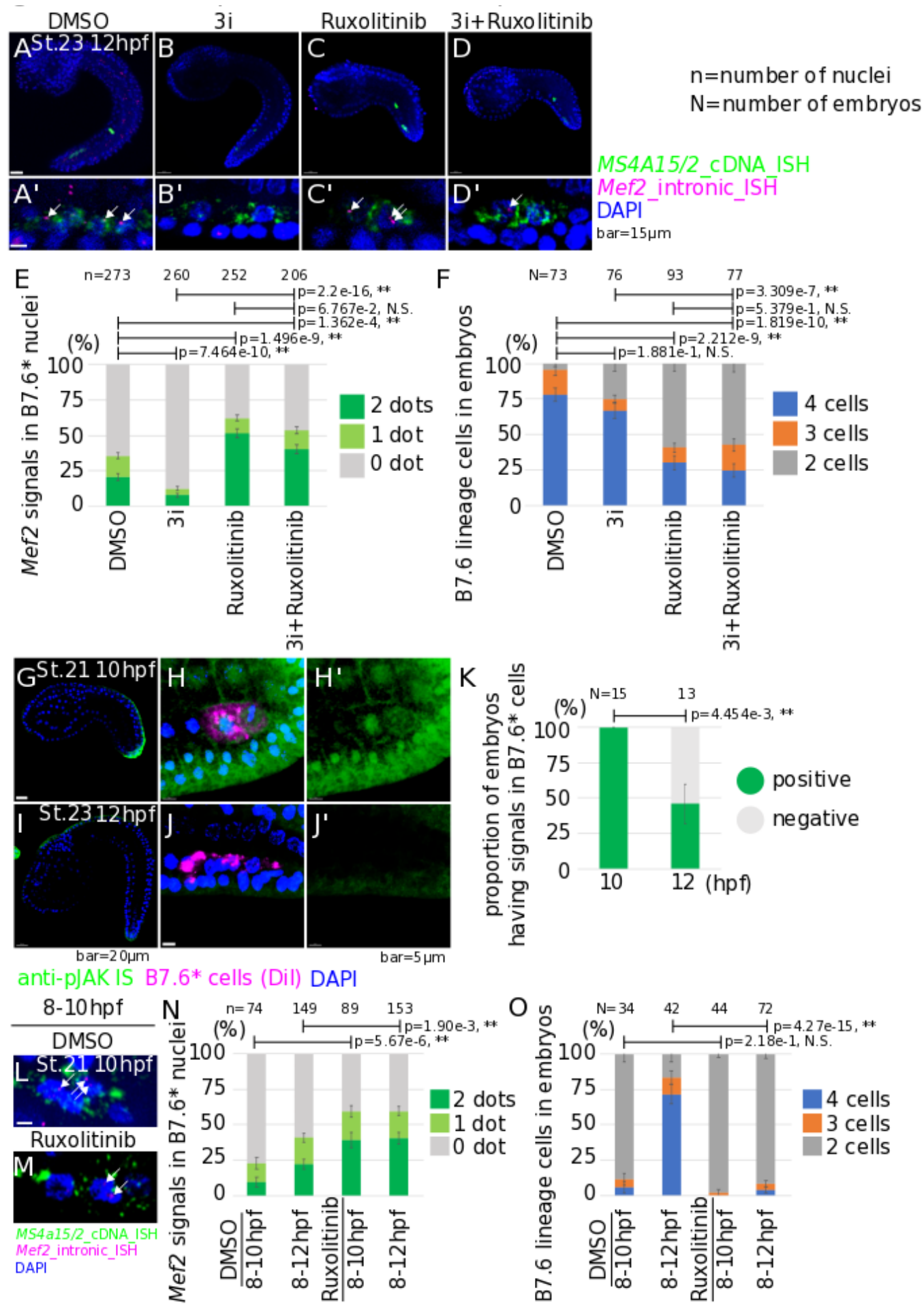

Figure 3. Mef2 nascent expression in inhibitor treated embryos. (A-D) ISH was done with Mef2 intronic probes under each pharmacological inhibitor treatment; DMSO (A), 3i (B), Ruxolitinib (C) and $3 \mathrm{i}+$ Ruxolitinib (D). White arrows show the dotted signals of nascent Mef2 expression. Scale bars $=15 \mu \mathrm{m}$. (E) Proportion of Mef2 signals in nuclei under each pharmacological inhibitor treatment. (F) Proportion of cell numbers of $\mathrm{B} 7.6^{*}$ cells in embryos under each pharmacological inhibitor treatment. (G-J) Immunostaining with anti-JAK2 antibody was done at the mid tailbud; $10 \mathrm{hpf}$ (G-H') and the late tailbud; $12 \mathrm{hpf}\left(\mathrm{I}-\mathrm{J}^{\prime}\right)$ stages. Scale bar $=5 \mu \mathrm{m}$. (K) Proportion of embryo that have positive signals in B7.6* cells by 
immunostaining with anti-JAK2 antibody. (L-M) ISH was done with Mef2 intronic probes under each pharmacological inhibitor treatment; DMSO (L) and Ruxolitinib (M) in $10 \mathrm{hpf}$ embryos. White arrows

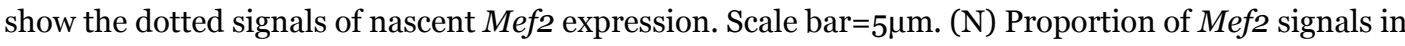
nuclei under each condition. (O) Proportion of cell numbers of $\mathrm{B} 7.6^{*}$ cells in embryos under each condition. Error bars indicate standard error. p-value was calculated by z-test. p>0.05; N.S, 0.05>p>0.01; *, $0.01>\mathrm{p} ;{ }^{* *}$. 


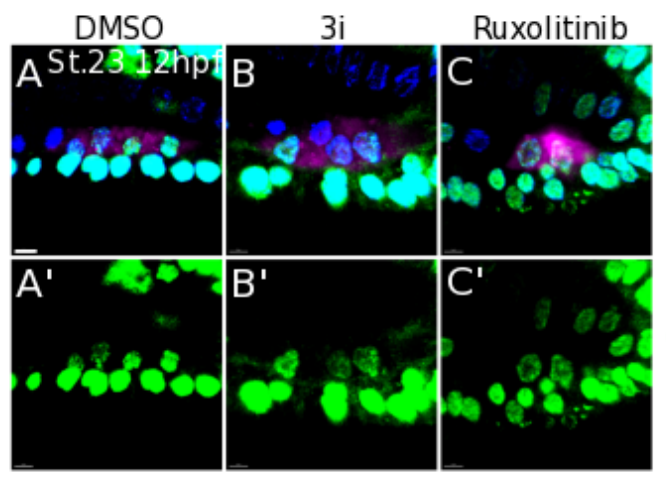

D RNAPII-pSer2 signals in nuclei
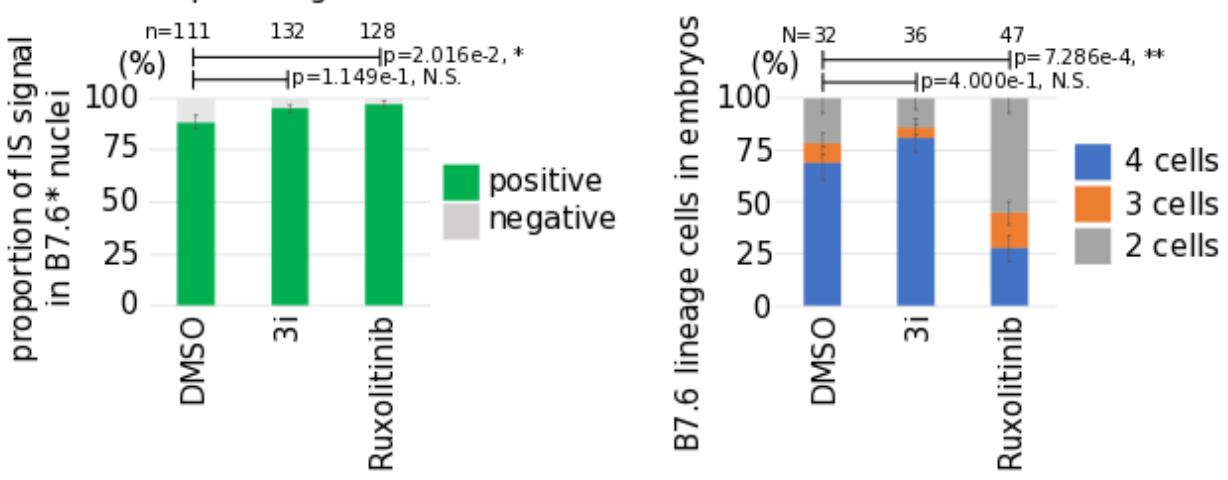

F

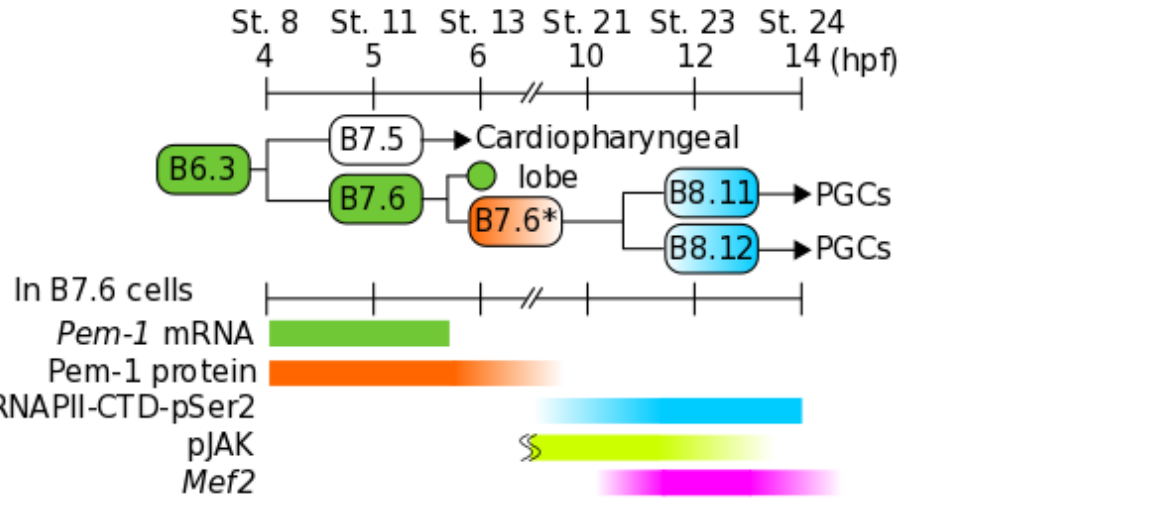

G

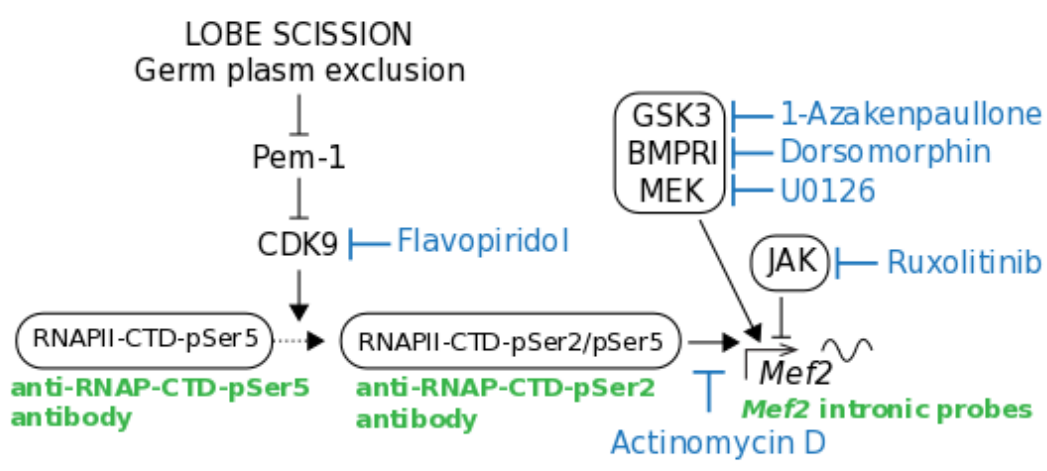

Figure 4. (A-C) Immunostaining was done with anti-RNAPII-CTD-pSer2 antibody under each pharmacological inhibitor treatment at $12 \mathrm{hpf}$. Scale bar=5 $\mu \mathrm{m}$. (D) Proportion of signals of immunostaining with anti-RNAPII-CTD-pSer2 antibody in nuclei under each pharmacological inhibitor treatment. (E) Proportion of cell numbers of B7.6* cells in embryos under each pharmacological inhibitor treatment. Error bars indicate standard error. p-value was calculated by z-test. p>0.05; N.S, 0.05>p>0.01; 
*, $0.01>\mathrm{p} ;{ }^{* *}$. (F) A schematic image for activity or presence of each factor in B7.6 and B7.6* cells based on this study and the previous report ${ }^{17}$. (G) Working scheme of onset of zygotic transcription in B7.6* cells that was drawn in this study.

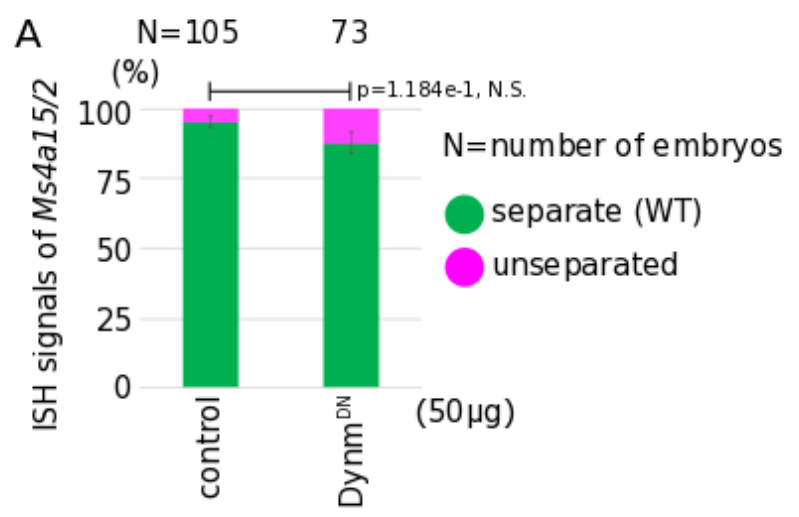

Supplemental Figure S1. (A) ISH signals of MS4a15/2 in lobe or B7.6 cells were scored in embryos at the late tailbud stage, St.23. Error bars indicate standard error. p-value was calculated by z-test. p>0.05; N.S, $0.05>\mathrm{p}>0.01 ;{ }^{*}, 0.01>\mathrm{p} ;{ }^{* *}$.

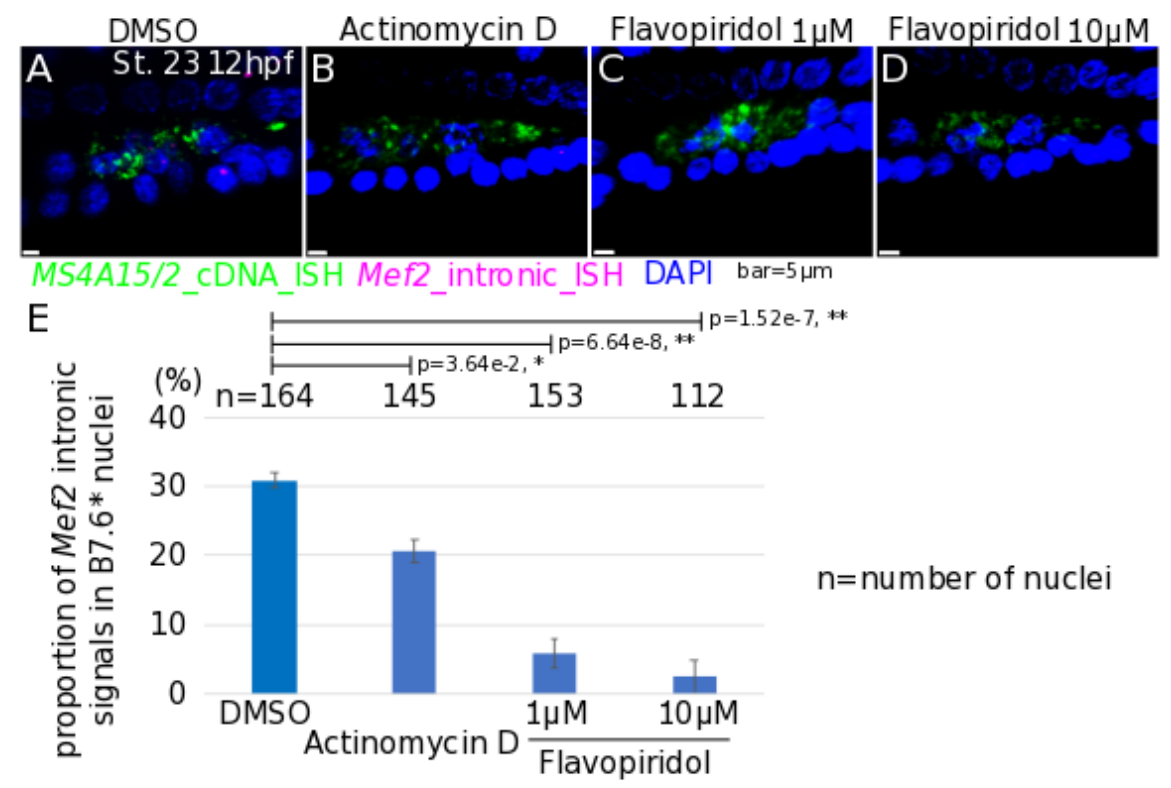

Supplemental Figure S2. (A-D) Nascent expression of Mef2 in embryos treated by: DMSO (A), Actinomycin D (B), $1 \mu \mathrm{M}(\mathrm{C})$ and $10 \mu \mathrm{M}$ (D) Flavopiridol. Scale bar=5 $5 \mathrm{~m}$ (E) Proportion of Mef2 signals in nuclei in B7.6* cells. Error bars indicate standard error. p-value was calculated by z-test. p>0.05; N.S, $0.05>\mathrm{p}>0.01 ;{ }^{*}, 0.01>\mathrm{p}$; **. 


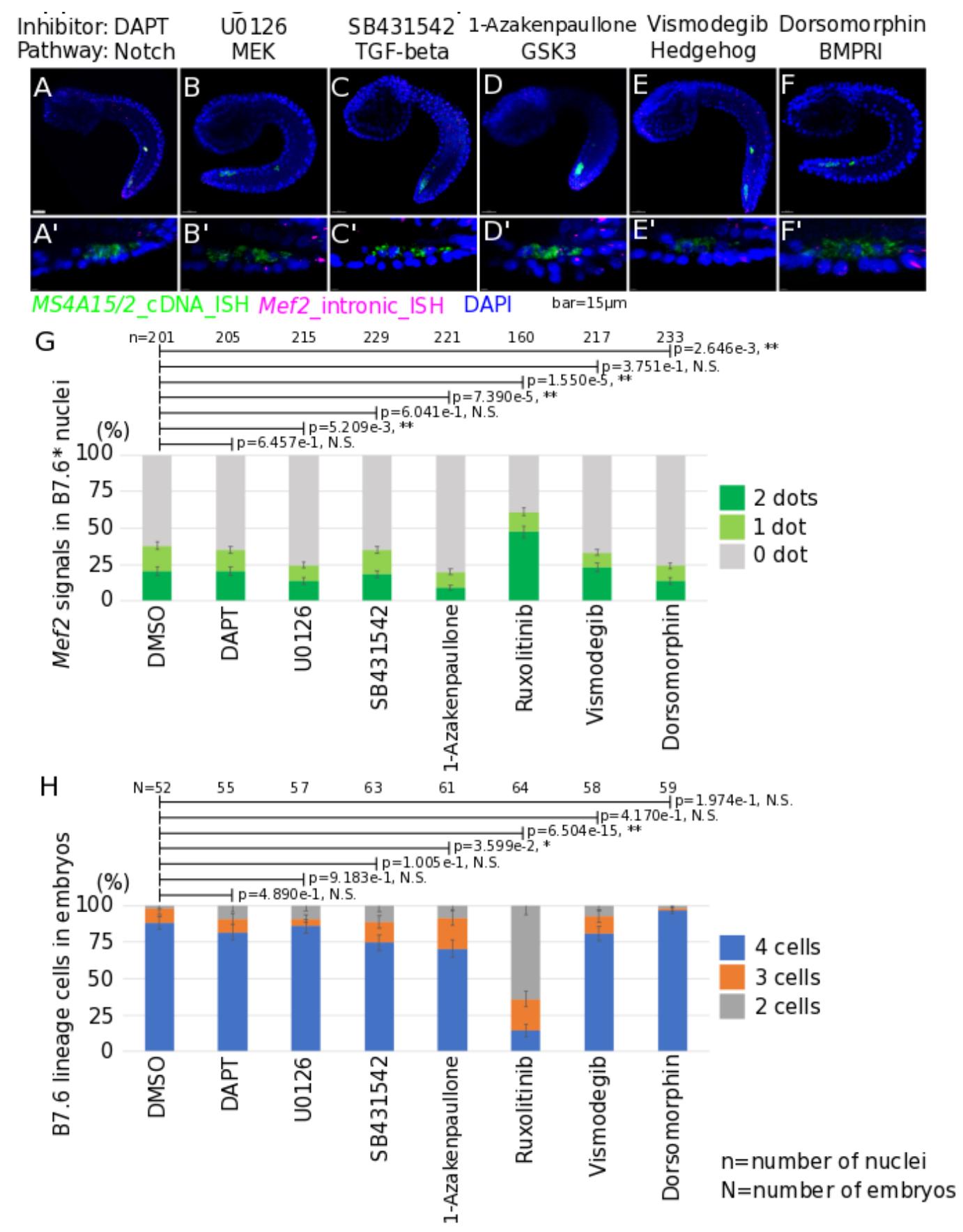

Supplemental Figure S3. (A-F) ISH was done with Mef2 intronic probes under each pharmacological inhibitor treatment. Scale bar $=15 \mu \mathrm{m}$. (G) Proportion of Mef2 signals in nuclei of B7.6* cells under each pharmacological inhibitor treatment. $(\mathrm{H})$ Proportion of cell numbers of B7.6* cells in embryos under each pharmacological inhibitor treatment. Error bars indicate standard error. p-value was calculated by z-test. p>0.05; N.S, 0.05>p>0.01; * $0.01>\mathrm{p} ;{ }^{* *}$. 
A

Ciona JAK 930 NGV----AEPSLRIVMEYLPYGSLSHFLRGQRDSGIALQQ 965

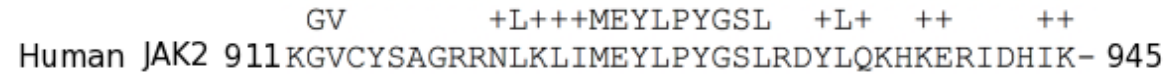

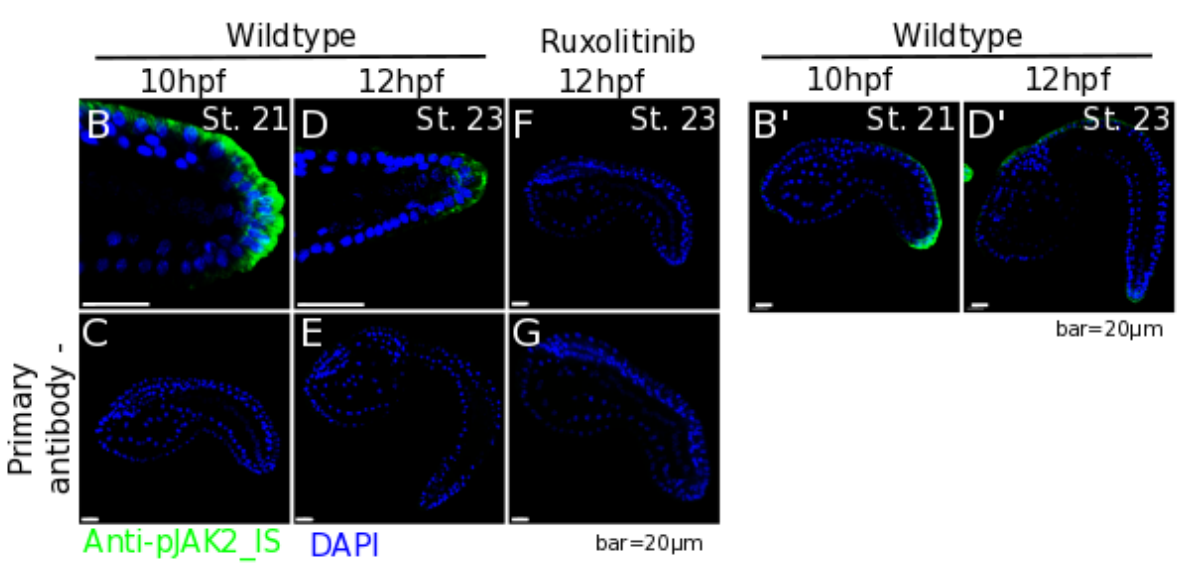

Supplemental Figure S4. (A) Aliment of protein sequences of JAK in Ciona and JAK2 in Human. Amino acid residues 930-965 in Ciona JAK are shown. The conserved actively phosphorylated Tyrosines is marked by *. (B, D, F) Immunostaining was done with anti-pJAK2 antibody in DMSO control at $10 \mathrm{hpf}$ (B) and $12 \mathrm{hpf}(\mathrm{D})$, and Ruxolitinib treated embryos at $12 \mathrm{hpf}(\mathrm{F})$. (B', D') Whole embryo images of B and D, respectively. (C, E, F) No primary antibody controls corresponding to B, D and F, respectively. Scale bar $=20 \mu \mathrm{m}$. Images around the tail tip are shown in B and D.

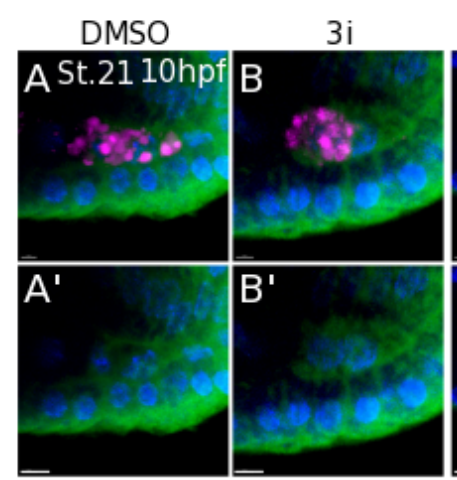

$\mathrm{E}$

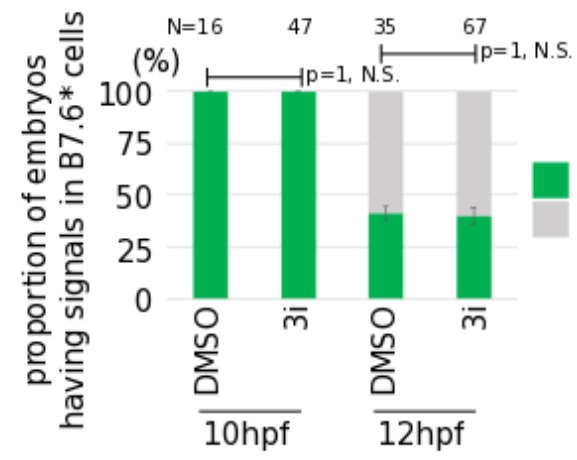

DMSO
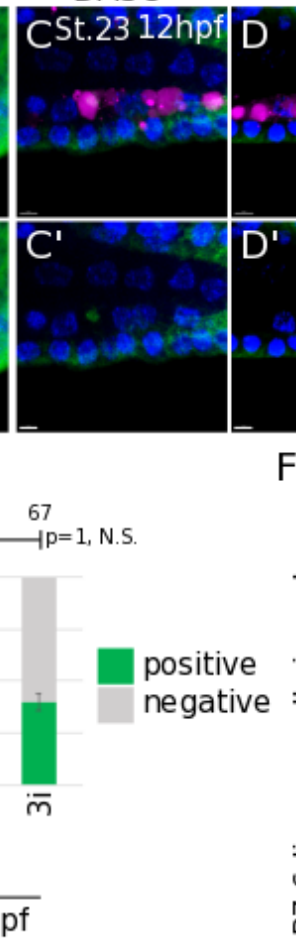

$3 i$
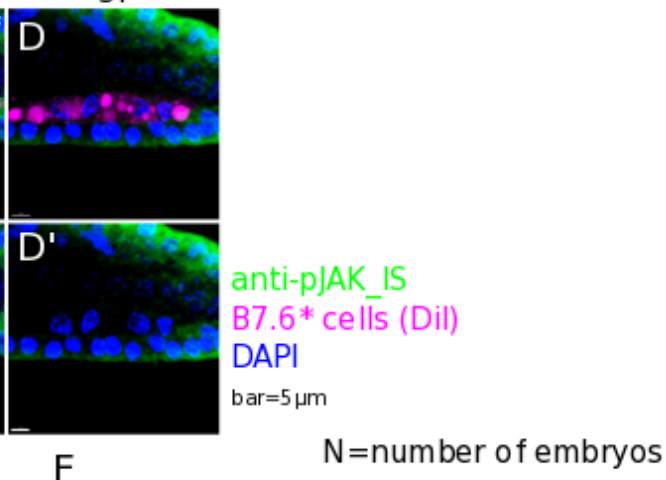
Supplemental Figure S5. (A-D) Immunostaining was done with anti-JAK2 antibody under $3 \mathrm{i}$ pharmacological inhibitors treatment at $10 h p f(A, B)$ and $12 \mathrm{hpf}(\mathrm{C}, \mathrm{D})$. Scale bar $=5 \mu \mathrm{m}$. (E) Proportion of signals of immunostaining with anti-pJAK2 antibody in $7.6^{*}$ cells. (F) Proportion of cell numbers of B7.6* cells in embryos. Error bars indicate standard error. p-value was calculated by z-test. p>0.05; N.S, $0.05>\mathrm{p}>0.01 ;{ }^{*}, 0.01>\mathrm{p}$; **.

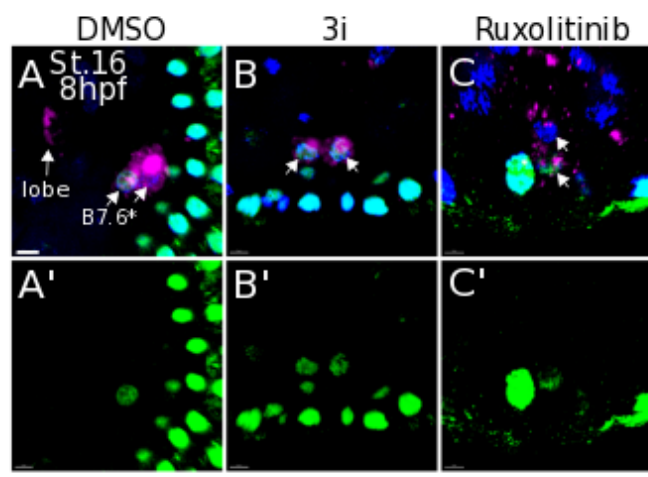

D RNAPII-pSer2 signals in nuclei
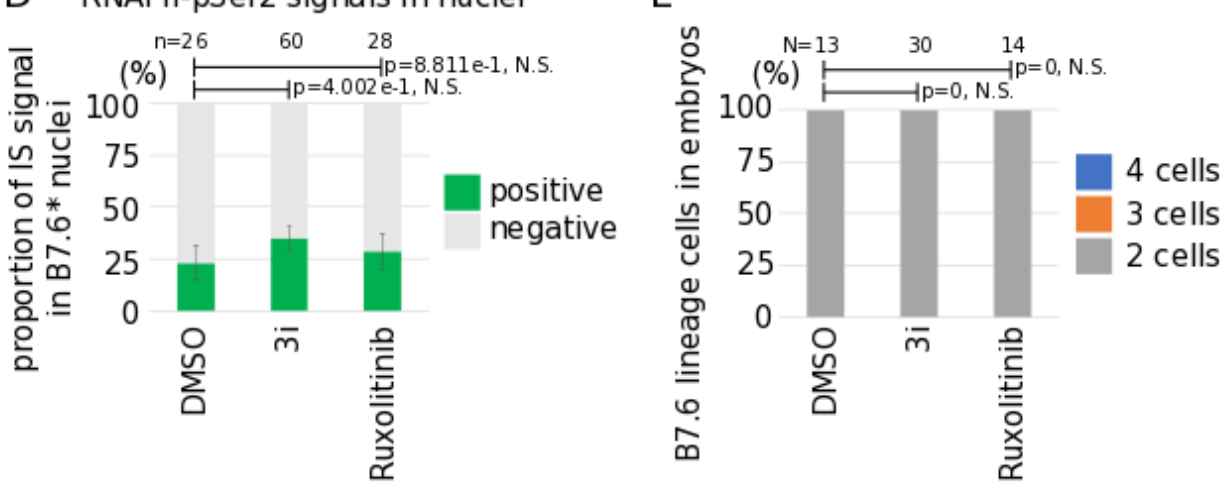

Supplemental Figure S6. (A-C) Immunostaining was done with anti-RNAPII-CTD-pSer2 antibody under each pharmacological inhibitor treatment at $8 \mathrm{hpf}$. Scale bar $=5 \mu \mathrm{m}$. (D) Proportion of signals of immunostaining with anti-RNAPII-CTD-pSer2 antibody in nuclei under each pharmacological inhibitor treatment. (E) Proportion of cell numbers of B7.6* cells in embryos under each pharmacological inhibitor treatment. Error bars indicate standard error. p-value was calculated by z-test. p>0.05; N.S, 0.05>p>0.01; ${ }^{*}, 0.01>\mathrm{p} ;{ }^{* *}$.

\section{Supplemental Table.S1 Primers}

\begin{tabular}{llll}
\hline Gene name & Type & & Primers sequence \\
\hline Mef2 & intron & Fonward & 5'-ACTCCATGCCCACTTACGAA-3' \\
& & Reverse & 5'-GGATCGCGATGTAAAGGACG-3' \\
& intron & Forward & 5'-CGACACACCCGTAATCTGG-3' \\
& & Reverse & 5'-GGGGATGTAGTCTGAAGGGG-3' \\
MS4A15/2 & exon & Fonward & 5'-CAAAGGAAATGTCAGTIAC-3' \\
& & Reverse & 5'-GTTCCAGAAACTAAATAAG-3' \\
Pem-1 & exon & Fonward & 5'-AAAGAAAGTGCATAAATATG-3' \\
& & Reverse & 5'-AATCGTGAAAAAGTACTAAC-3' \\
\hline
\end{tabular}


bioRxiv preprint doi: https://doi.org/10.1101/2021.07.12.452040; this version posted November 9, 2021. The copyright holder for this preprint (which was not certified by peer review) is the author/funder. All rights reserved. No reuse allowed without permission. 


\section{References}

1. Moris, N., Pina, C. \& Arias, A. M. Transition states and cell fate decisions in epigenetic landscapes. Nat. Rev. Genet. 17, 693-703 (2016).

2. Nimmo, R. A., May, G. E. \& Enver, T. Primed and ready: understanding lineage commitment through single cell analysis. Trends Cell Biol. 25, 459-467 (2015).

3. Razy-Krajka, F. et al. Collier/OLF/EBF-dependent transcriptional dynamics control pharyngeal muscle specification from primed cardiopharyngeal progenitors. Dev. Cell 29, 263-276 (2014).

4. $\mathrm{Hu}, \mathrm{M}$. et al. Multilineage gene expression precedes commitment in the hemopoietic system. Genes Dev. 11, 774-785 (1997).

5. Wang, W. et al. A single-cell transcriptional roadmap for cardiopharyngeal fate diversification. Nat. Cell Biol. 21, 674-686 (2019).

6. Graf, T. \& Enver, T. Forcing cells to change lineages. Nature 462, 587-594 (2009).

7. Wang, W., Razy-Krajka, F., Siu, E., Ketcham, A. \& Christiaen, L. NK4 antagonizes Tbx1/10 to promote cardiac versus pharyngeal muscle fate in the ascidian second heart field. PLoS Biol. 11, e1001725 (2013).

8. Levine, M. \& Tjian, R. Transcription regulation and animal diversity. Nature 424, 147-151 (2003).

9. Davidson, E. H. \& Levine, M. S. Properties of developmental gene regulatory networks. Proc. Natl. Acad. Sci. U. S. A. 105, 20063-20066 (2008).

10. Levine, M. \& Davidson, E. H. Gene regulatory networks for development. Proc. Natl. Acad. Sci. U.S. A. 102, 4936-4942 (2005).

11. Ohinata, Y. et al. A signaling principle for the specification of the germ cell lineage in mice. Cell 137, 571-584 (2009).

12. Tang, W. W. C., Kobayashi, T., Irie, N., Dietmann, S. \& Surani, M. A. Specification and epigenetic programming of the human germ line. Nat. Rev. Genet. 17, 585-60o (2016).

13. Mitsunaga, S. \& Shioda, T. Evolutionarily diverse mechanisms of germline specification among mammals: what about us? Stem cell investigation vol. 512 (2018).

14. Jostes, S. \& Schorle, H. Signals and transcription factors for specification of human germ cells. Stem cell investigation vol. 513 (2018).

15. Nakamura, A. \& Seydoux, G. Less is more: specification of the germline by transcriptional repression. Development 135, 3817-3827 (2008)

16. Kumano, G., Takatori, N., Negishi, T., Takada, T. \& Nishida, H. A maternal factor unique to ascidians silences the germline via binding to
P-TEFb and RNAP II regulation. Curr. Biol. 21, 1308-1313 (2011).

17. Shirae-Kurabayashi, M., Matsuda, K. \& Nakamura, A. Ci-Pem-1 localizes to the nucleus and represses somatic gene transcription in the germline of Ciona intestinalis embryos. Development 138, 2871-2881 (2011).

18. Robert, V. J., Garvis, S. \& Palladino, F. Repression of somatic cell fate in the germline. Cell. Mol. Life Sci. 72, 3599-3620 (2015).

19. Lebedeva, L. A. et al. Transcriptional quiescence in primordial germ cells. Crit. Rev. Biochem. Mol. Biol. 53, 579-595 (2018).

20. Seydoux, G. \& Dunn, M. A. Transcriptionally repressed germ cells lack a subpopulation of phosphorylated RNA polymerase II in early embryos of Caenorhabditis elegans and Drosophila melanogaster. Development 124, 2191-2201 (1997).

21. Batchelder, C. et al. Transcriptional repression by the Caenorhabditis elegans germ-line protein PIE-1. Genes Dev. 13, 202-212 (1999).

22. Blackwell, T. K. Germ cells: finding programs of mass repression. Curr. Biol. 14, R229-30 (2004).

23. Seydoux, G. \& Braun, R. E. Pathway to totipotency: lessons from germ cells. Cell 127, 891-904 (2006).

24. Hanyu-Nakamura, K., Sonobe-Nojima, H., Tanigawa, A., Lasko, P. \& Nakamura, A. Drosophila Pgc protein inhibits P-TEFb recruitment to chromatin in primordial germ cells. Nature 451, 730-733 (2008).

25. Mello, C. C. et al. The PIE-1 protein and germline specification in C. elegans embryos. Nature vol. 382 710-712 (1996).

26. Nakamura, A., Amikura, R., Mukai, M., Kobayashi, S. \& Lasko, P. F. Requirement for a Noncoding RNA in Drosophila Polar Granules for Germ Cell Establishment. Science vol. 274 2075-2079 (1996).

27. Yoshida, S., Marikawa, Y. \& Satoh, N. Posterior end mark, a novel maternal gene encoding a localized factor in the ascidian embryo. Development vol. 122 2005-2012 (1996).

28. Sasakura, Y., Ogasawara, M. \& Makabe, K. W. Two pathways of maternal RNA localization at the posterior-vegetal cytoplasm in early ascidian embryos. Dev. Biol. 220, 365-378 (2000).

29. Prodon, F., Yamada, L., Shirae-Kurabayashi, M., Nakamura, Y. \& Sasakura, Y. Postplasmic/PEM RNAs: a class of localized maternal mRNAs with multiple roles in cell polarity and development in ascidian embryos. Dev. Dyn. 236, 1698-1715 (2007).

30. Shirae-Kurabayashi, M. et al. Dynamic redistribution of vasa homolog and exclusion of somatic cell determinants during germ cell 
specification in Ciona intestinalis.

Development 133, 2683-2693 (2006).

31. Dehal, P. et al. The draft genome of Ciona intestinalis: insights into chordate and vertebrate origins. Science 298, 2157-2167 (2002).

32. Yamada, L., Kobayashi, K., Satou, Y. \& Satoh, N. Microarray analysis of localization of maternal transcripts in eggs and early embryos of the ascidian, Ciona intestinalis. Dev. Biol. 284, 536-550 (2005).

33. Yamada, L. Embryonic expression profiles and conserved localization mechanisms of pem/postplasmic mRNAs of two species of ascidian, Ciona intestinalis and Ciona savignyi. Dev. Biol. 296, 524-536 (2006).

34. Imai, K. S., Levine, M., Satoh, N. \& Satou, Y. Regulatory blueprint for a chordate embryo. Science 312, 1183-1187 (2006).

35. Ohta, N. \& Satou, Y. Multiple signaling pathways coordinate to induce a threshold response in a chordate embryo. PLoS Genet. 9, e1003818 (2013).

36. Satou, Y. \& Imai, K. S. Gene regulatory systems that control gene expression in the Ciona embryo. Proc. Jpn. Acad. Ser. B Phys. Biol. Sci. 91, 33-51 (2015).

37. Oda-Ishii, I. et al. A Maternal System Initiating the Zygotic Developmental Program through Combinatorial Repression in the Ascidian Embryo. PLoS Genet. 12, e1006045 (2016).

38. Christiaen, L., Wagner, E., Shi, W. \& Levine, M. Isolation of sea squirt (Ciona) gametes, fertilization, dechorionation, and development. Cold Spring Harb. Protoc. 2oo9, db.prot5344 (2009).

39. Satou, Y., Imai, K. S. \& Satoh, N. The ascidian Mesp gene specifies heart precursor cells. Development 131, 2533-2541 (2004).

40. Christiaen, L., Wagner, E., Shi, W. \& Levine, M. Electroporation of transgenic DNAs in the sea squirt Ciona. Cold Spring Harb. Protoc. 2009, db.prot5345 (2009).

41. Christiaen, L., Wagner, E., Shi, W. \& Levine, M. Whole-mount in situ hybridization on sea squirt (Ciona intestinalis) embryos. Cold Spring Harb. Protoc. 2009, db.prot 5348 (2009).

42. Miyaoku, K., Nakamoto, A., Nishida, H. \& Kumano, G. Control of Pem protein level by localized maternal factors for transcriptional regulation in the germline of the ascidian, Halocynthia roretzi. PLOS ONE vol. 13 e0196500 (2018).

43. Feinberg, S., Roure, A., Piron, J. \& Darras, S. Antero-posterior ectoderm patterning by canonical Wnt signaling during ascidian development. PLoS Genet. 15, e1008054 (2019).

44. Hudson, C., Darras, S., Caillol, D., Yasuo, H. \& Lemaire, P. A conserved role for the MEK signalling pathway in neural tissue specification and posteriorisation in the invertebrate chordate, the ascidian Ciona intestinalis. Development 130, 147-159 (2003).

45. Takamura, K., Fujimura, M. \& Yamaguchi, Y. Primordial germ cells originate from the endodermal strand cells in the ascidian Ciona intestinalis. Dev. Genes Evol. 212, 11-18 (2002).

46. Tassy, O. et al. The ANISEED database: digital representation, formalization, and elucidation of a chordate developmental program. Genome Res. 20, 1459-1468 (2010).

47. Dardaillon, J. et al. ANISEED 2019: 4D exploration of genetic data for an extended range of tunicates. Nucleic Acids Res. 48, D668-D675 (2020).

48. Brozovic, M. et al. ANISEED 2017: extending the integrated ascidian database to the exploration and evolutionary comparison of genome-scale datasets. Nucleic Acids Res. 46, D718-D725 (2018).

49. Nishikata, T. et al. Profiles of maternally expressed genes in fertilized eggs of Ciona intestinalis. Dev. Biol. 238, 315-331 (2001).

50. Hotta, K. et al. A web-based interactive developmental table for the ascidian Ciona intestinalis, including 3D real-image embryo reconstructions: I. From fertilized egg to hatching larva. Dev. Dyn. 236, 1790-1805 (2007).

51. Abdu, Y., Maniscalco, C., Heddleston, J. M., Chew, T.-L. \& Nance, J. Developmentally programmed germ cell remodelling by endodermal cell cannibalism. Nature Cell Biology vol. 18 1302-1310 (2016).

52. Mainpal, R., Nance, J. \& Yanowitz, J. L. A germ cell determinant reveals parallel pathways for germ line development in Caenorhabditis elegans. Development 142, 3571-3582 (2015).

53. Maniscalco, C., Hall, A. E. \& Nance, J. An interphase contractile ring reshapes primordial germ cells to allow bulk cytoplasmic remodeling. J. Cell Biol. 219, (2020).

54. McIntyre, D. C. \& Nance, J. Niche Cell Wrapping Ensures Primordial Germ Cell Quiescence and Protection from Intercellular Cannibalism. Curr. Biol. 3o, 708-714.e4 (2020).

55. Ying, Ying, Y., Qi, X. \& Zhao, G.-Q. Induction of Primordial Germ Cells from Pluripotent Epiblast. The Scientific World JOURNAL vol. 2 801-810 (2002).

56. Pilato, G. et al. The problem of the origin of primordial germ cells (PGCs) in vertebrates: historical review and a possible solution. The International Journal of Developmental Biology vol. 57 809-819 (2013).

57. Nishida, H. \& Satoh, N. Cell lineage analysis in ascidian embryos by intracellular injection of a tracer enzyme. I. Up to the eight-cell stage. Dev. Biol. 99, 382-394 (1983). 
58. Kawai, N. et al. Hox10-regulated endodermal cell migration is essential for development of the ascidian intestine. Dev. Biol. 403, 43-56 (2015).

59. Ristoratore, F. et al. Expression and functional analysis of Cititf1, an ascidian NK-2 class gene, suggest its role in endoderm development. Development 126, 5149-5159 (1999).

6o. Gline, S., Kaplan, N., Bernadskaya, Y., Abdu, Y. \& Christiaen, L. Surrounding tissues canalize motile cardiopharyngeal progenitors towards collective polarity and directed migration. Development vol. 142 544-554 (2015).

61. Imai, K. S. Gene expression profiles of transcription factors and signaling molecules in the ascidian embryo: towards a comprehensive understanding of gene networks. Development vol. 131 4047-4058 (2004).

62. Razy-Krajka, F. et al. An FGF-driven feed-forward circuit patterns the cardiopharyngeal mesoderm in space and time. Elife 7, (2018).

63. Gregor, T., Garcia, H. G. \& Little, S. C. The embryo as a laboratory: quantifying transcription in Drosophila. Trends Genet. 3o, 364-375 (2014).

64. Tkačik, G. \& Gregor, T. The many bits of positional information. Development 148 , (2021).

65. Sobell, H. M. Actinomycin and DNA transcription. Proc. Natl. Acad. Sci. U. S. A. 82, 5328-5331 (1985).

66. Bensaude, O. Inhibiting eukaryotic transcription: Which compound to choose? How to evaluate its activity? Transcription 2, 103-108 (2011).

67. Waki, K., Imai, K. S. \& Satou, Y. Genetic pathways for differentiation of the peripheral nervous system in ascidians. Nature Communications vol. 6 (2015).

68. Harder, M., Reeves, W., Byers, C., Santiago, M. \& Veeman, M. Multiple inputs into a posterior-specific regulatory network in the Ciona notochord. Dev. Biol. 448, 136-146 (2019).

69. Hino, K., Satou, Y., Yagi, K. \& Satoh, N. A genomewide survey of developmentally relevant genes in Ciona intestinalis. VI. Genes for Wnt, TGFbeta, Hedgehog and JAK/STAT signaling pathways. Dev. Genes Evol. 213, 264-272 (2003).

70. Kutschera, U. \& Niklas, K. J. The modern theory of biological evolution: an expanded synthesis. Naturwissenschaften 91, 255-276 (2004).

71. Dröscher, A. Images of cell trees, cell lines, and cell fates: the legacy of Ernst Haeckel and August Weismann in stem cell research. Hist. Philos. Life Sci. 36, 157-186 (2014).

72. Weismann, A. Das Keimplasma: eine Theorie der Vererbung. (1892).

73. Kang, M. K. \& Han, S. J. Post-transcriptional and post-translational regulation during mouse oocyte maturation. BMB Rep. 44, 147-157 (2011).

74. Hayashi, K. \& Saitou, M. Perspectives of germ cell development in vitro in mammals. Animal Science Journal vol. 85 617-626 (2014).

75. Bhartiya, D., Anand, S., Patel, H. \& Parte, S. Making gametes from alternate sources of stem cells: past, present and future. Reprod. Biol. Endocrinol. 15, 89 (2017).

76. Strome, S. \& Updike, D. Specifying and protecting germ cell fate. Nat. Rev. Mol. Cell Biol. 16, 406-416 (2015).

77. Lehmann, R. Germline Stem Cells: Origin and Destiny. Cell Stem Cell vol. 10 729-739 (2012).

78. Trcek, T. \& Lehmann, R. Germ granules in Drosophila. Traffic 2o, 650-660 (2019).

79. Sardet, C., Paix, A., Prodon, F., Dru, P. \& Chenevert, J. From oocyte to 16-cell stage: cytoplasmic and cortical reorganizations that pattern the ascidian embryo. Dev. Dyn. 236, 1716-1731 (2007).

8o. Little, S. C., Sinsimer, K. S., Lee, J. J., Wieschaus, E. F. \& Gavis, E. R. Independent and coordinate trafficking of single Drosophila germ plasm mRNAs. Nat. Cell Biol. 17, 558-568 (2015).

81. Paix, A. et al. Cortical anchorages and cell type segregations of maternal postplasmic/PEM RNAs in ascidians. Dev. Biol. 336, 96-111 (2009).

82. D’Orazio, F. M. et al. Germ cell differentiation requires Tdrd7-dependent chromatin and transcriptome reprogramming marked by germ plasm relocalization. Dev. Cell 56, 641-656.e5 (2021).

83. Olsen, L. C. et al. Evidence for a centrosome-attracting body like structure in germ-soma segregation during early development, in the urochordate Oikopleura dioica. BMC Dev. Biol. 18, 4 (2018).

84. Chenevert, J., Pruliere, G., Ishii, H., Sardet, C. \& Nishikata, T. Purification of mitochondrial proteins HSP6o and ATP synthase from ascidian eggs: implications for antibody specificity. PLoS One 8, e52996 (2013).

85. Anderson, R., Copeland, T. K., Schöler, H., Heasman, J. \& Wylie, C. The onset of germ cell migration in the mouse embryo. Mech. Dev. 91, 61-68 (2000).

86. Kanamori, M., Oikawa, K., Tanemura, K. \& Hara, K. Mammalian germ cell migration during development, growth, and homeostasis. Reprod. Med. Biol. 18, 247-255 (2019).

87. Karaiskou, A., Swalla, B. J., Sasakura, Y. \& Chambon, J.-P. Metamorphosis in solitary ascidians. Genesis 53, 34-47 (2015).

88. Krasovec, G., Robine, K., Quéinnec, E., Karaiskou, A. \& Chambon, J. P. Ci-hox12 tail gradient precedes and participates in the control of the apoptotic-dependent tail regression during Ciona larva metamorphosis. 
Dev. Biol. 448, 237-246 (2019).

89. Lawson, K. A. et al. Bmp4 is required for the generation of primordial germ cells in the mouse embryo. Genes \& development vol. 13 424-436 (1999).

90. Yu, L. et al. Derivation of Intermediate Pluripotent Stem Cells Amenable to Primordial Germ Cell Specification. Cell Stem Cell (2020) doi:10.1016/j.stem.2020.11.003.

91. Ying, Q.-L. et al. The ground state of embryonic stem cell self-renewal. Nature 453, 519-523 (2008).

92. Hanna, J. et al. Human embryonic stem cells with biological and epigenetic characteristics similar to those of mouse ESCs. Proc. Natl. Acad. Sci. U. S. A. 107, 9222-9227 (2010).

93. Gafni, O. et al. Derivation of novel human ground state naive pluripotent stem cells. Nature 504, 282-286 (2013).

94. Ware, C. B. et al. Derivation of naive human embryonic stem cells. Proc. Natl. Acad. Sci. U. S. A. 111, 4484-4489 (2014).

95. Takashima, Y. et al. Resetting Transcription Factor Control Circuitry toward Ground-State Pluripotency in Human. Cell 162, 452-453

(2015). 